\title{
Kinetics and mechanism of intramolecular carboxylic acid participation in the hydrolysis of $N$-methoxyphthalamic acid
}

\author{
M. Niyaz Khan * and Azhar Ariffin \\ Department of Chemistry, Faculty of Science, University of Malaya, 50603 Kuala Lumpur, \\ Malaysia
}

Received 16th January 2003, Accepted 26th February 2003

First published as an Advance Article on the web 18th March 2003

The rate of formation and disappearance of phthalic anhydride (PAn) intermediate in the aqueous cleavage of $\mathrm{N}$-methoxyphthalamic acid (NMPA) under acidic pH was studied spectrophotometrically in mixed $\mathrm{CH}_{3} \mathrm{CN}-\mathrm{H}_{2} \mathrm{O}$ solvents. The rate of formation of PAn from NMPA is almost independent of the change in acetonitrile content from 20 to $70 \% \mathrm{v} / \mathrm{v}$ in mixed aqueous solvents. The rate constants for the formation of PAn from NMPA are $~ 10$-fold smaller than the corresponding rate constants for the formation of PAn from $o$-carboxybenzohydroxamic acid (OCBA). These observations are ascribed to the consequence of the occurrence of slightly different mechanisms in these reactions.

\section{Introduction}

Intramolecular carboxylic acid participation in the hydrolytic cleavage of amide bonds has been the subject of much interest since the appearance of classic papers on the hydrolysis of phthalamic acid. ${ }^{1}$ Major aspects of the mechanism of these reactions are already well understood. ${ }^{1-11}$ The brief general mechanism, involved in these reactions, is shown in Scheme 1. Pseudo-first-order rate constants $\left(k_{\text {obs }}\right)$ for hydrolysis of $N$-substituted phthalamic and related acids gave negative $\rho$ (Hammett reaction constant) and $\rho^{*}$ (Taft reaction constant) ${ }^{6-9} \dagger$ The value of $\rho$ or $\rho^{*}$ for equilibrium constant $K_{\mathrm{f}}$ in Scheme 1 is expected to be positive. Since experimentally observed value of $\rho$ or $\rho^{*}$ is the sum of $\rho$ or $\rho^{*}$ for $K_{\mathrm{f}}$ and for $k$, $k_{\mathrm{gb}}$ or $k_{\mathrm{ga}}$ (Scheme 1) and therefore the observed negative value of $\rho$ or $\rho^{*}$ reveals that $\rho$ or $\rho^{*}$ value for $k, k_{\mathrm{gb}}$ or $k_{\mathrm{ga}}$ must be negative with sufficiently high absolute magnitude to result in an overall negative value for observed reaction constant. Based upon the reported values of $\rho$ or $\rho^{*}$ in all such studies, (at least to the knowledge of these authors), the value of $k_{\text {obs }}$ for the hydrolytic cleavage of $o$-carboxybenzohydroxamic acid (OCBA) should be significantly smaller than that of phthalamic acid under similar experimental conditions. But, in
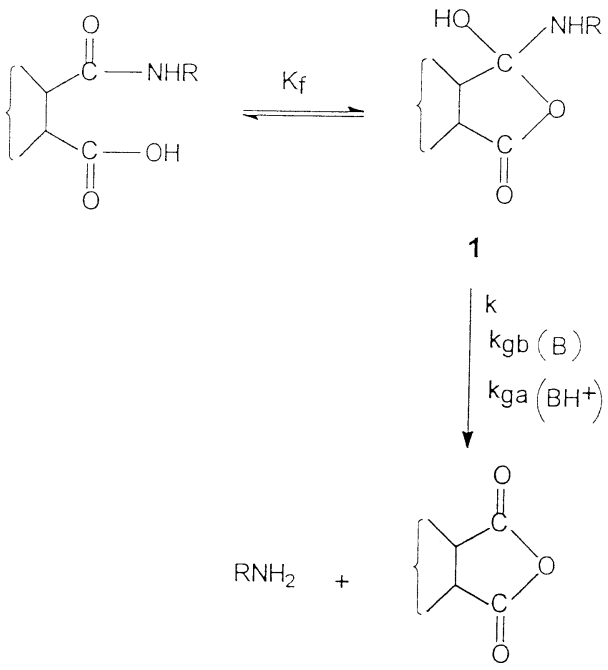

Scheme 1

$\dagger$ A referee has pointed out that the substituent parameters relate to substituents on aryl and alkyl groups because $\rho^{*}$ has been applied to ortho substituents contrast to this prediction, the value of $k_{\text {obs }}$ for the hydrolytic cleavage of OCBA turned out to be more than 10-fold larger than that of phthalamic acid. ${ }^{12}$

Unexpected and significantly high reactivity of OCBA compared to that of phthalamic acid may be attributed to the presence of internally hydrogen-bonded complex 2 (where the $\mathrm{OH}$ group of the $-\mathrm{NHOH}$ moiety provides intramolecular general acid catalysis for nucleophilic attack to form $\mathbf{1}$ ) or $\mathbf{3}$ (where the $\mathrm{OH}$ group of the $-\mathrm{NHOH}$ moiety provides intramolecular general base assistance to stabilize $\mathbf{1}$ ) in the formation of $\mathbf{1}$ (Scheme 1). It is apparent from the structural features of $\mathbf{2}$ and $\mathbf{3}$ that the presence of $\mathbf{2}$ is unlikely while that of $\mathbf{3}$ is likely in the hydrolytic cleavage of $N$-methoxyphthalamic acid (NMPA) under acidic $\mathrm{pH}$. Thus, the question whether $\mathbf{2}$ or $\mathbf{3}$ is involved in the hydrolytic cleavage of OCBA may be resolved by studying the rate of hydrolysis of NMPA under conditions similar to those used for OCBA. Intramolecular reactions are considered to be the model reactions for many enzyme-mediated reactions and it is widely believed that enzyme-mediated reactions occur in a micro reaction environment of considerably low water activity compared to that of pure water solvent. Thus, the effects of mixed aqueous-organic solvents on the rates of intramolecular reactions could provide valuable information regarding the effects of less hydrated reaction medium of enzyme-mediated reactions. The present study was initiated with an aim to resolve whether $\mathbf{2}$ or $\mathbf{3}$ is responsible for the unexpected rate enhancement observed in the hydrolytic cleavage of OCBA ${ }^{12}$ in mixed aqueous-acetonitrile solvents containing different contents of acetonitrile.

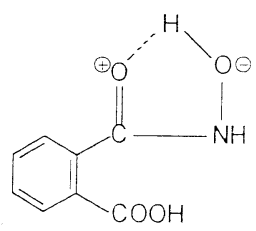

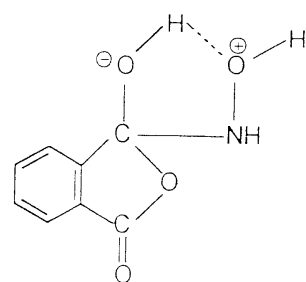

3

\section{Experimental}

\section{Materials}

$N$-Methoxyphthalimide (NMEPT) was synthesized from $N$-hydroxyphthalimide by using standard procedures and its purity was established by the use of ${ }^{1} \mathrm{H}$ NMR and ${ }^{13} \mathrm{C}$ NMR 
spectroscopic techniques. All other chemicals used were reagent grade commercial products. Stock solutions of NMEPT were frequently prepared in acetonitrile.

\section{Kinetics}

(a) Alkaline hydrolysis of NMEPT in mixed $\mathrm{H}_{2} \mathrm{O}-\mathrm{CH}_{3} \mathrm{CN}$ solvent. The rate of alkaline hydrolysis of $\mathrm{N}$-methoxyphthalimide (NMEPT) was studied spectrophotometrically by monitoring the disappearance of reactant (NMEPT) as a function of time at $300 \mathrm{~nm}$. The half-life periods, $t_{1 / 2}$, for the formation of phthalamic and $N$-substituted phthalamic acids from respective phthalimide and $N$-substituted phthalimides, and phthalic acid from phthalamic and $N$-substituted phthalamic acids, at $0.1 \mathrm{M}$ $\mathrm{NaOH}$ and $30{ }^{\circ} \mathrm{C}$ are $\sim 0.3 \mathrm{~s}$ and $17500 \mathrm{~h}$, respectively. ${ }^{13}$ Similarly, the rate of alkaline hydrolysis of $o$-carboxybenzohydroxamic acid was found to be negligible compared to the rate of alkaline hydrolysis of $N$-hydroxyphthalimide. ${ }^{14}$ Thus, the rate of alkaline hydrolysis of the immediate hydrolysis product ( $N$-methoxyphthalamic acid) of NMEPT should be insignificant compared to the rate of alkaline hydrolysis of NMEPT The details of the kinetic procedure may be seen elsewhere. ${ }^{15}$ Pseudo-first-order rate constants $\left(k_{\text {1obs }}\right)$ were calculated from eqn. (1)

$$
A_{\text {obs }}=\delta_{\text {app }}[\mathrm{X}]_{0} \exp \left(-k_{\text {1obs }} t\right)+A_{\infty}
$$

using a nonlinear least squares technique considering $\delta_{\text {app }}$ (apparent molar absorption coefficient) and $A_{\infty}$ (the absorbance at $t=\infty$ ) as unknown parameters. In eqn. (1), $A_{\text {obs }}$ is the absorbance at any reaction time, $t$, and $[\mathrm{X}]_{0}$ is the concentration of NMEPT at $t=0$. The observed data fitted well to eqn. (1) for up to 6-23 half-lives.

(b) Aqueous cleavage of $\mathrm{N}$-methoxyphthalamic acid (NMPA) under acidic medium in mixed $\mathrm{H}_{2} \mathrm{O}-\mathrm{CH}_{3} \mathrm{CN}$ solvent. The formation of phthalic anhydride (PAn) as a stable intermediate in the hydrolysis of phthalamic acid and its $N$-substituted derivatives under acidic medium has been unequivocally ascertained. ${ }^{1,8,11}$ Thus, the aqueous cleavage of NMPA under acidic medium is expected to follow an irreversible consecutive reaction path (eqn. (2))

$$
\text { NMPA } \stackrel{k_{20 b s}}{\longrightarrow} \text { PAn } \stackrel{k_{\text {sobs }}}{\longrightarrow} \text { PA }
$$

where PA represents phthalic acid, $k_{2 \text { obs }}$ and $k_{3 \text { obs }}$ represent pseudo-first-order rate constants for hydrolysis of NMPA and PAn, respectively. The values of $\delta$ (molar absorption coefficient) for phthalamic acid, PAn and PA, at $310 \mathrm{~nm}$ in pure water solvent, are $\sim 20, \sim 1000$ and $\sim 20 \mathrm{M}^{-1} \mathrm{~cm}^{-1}$, respectively. ${ }^{8}$ Thus, the rate of formation ( $k_{2 \mathrm{obs}}$-step) and decay $\left(k_{3 \mathrm{obs}}\right.$-step) of PAn were easily studied spectrophotometrically at $310 \mathrm{~nm}$ in mixed water-organic solvents. ${ }^{8,11-13}$

In a typical kinetic run with a total volume of $4.8 \mathrm{ml}$ of the reaction mixture containing $1.0 \mathrm{ml}$ of $0.01 \mathrm{M} \mathrm{N}$-methoxyphthalimide (NMEPT), $0.2 \mathrm{ml}$ of $0.5 \mathrm{M} \mathrm{NaOH}$ and required volume of acetonitrile, the reaction (i.e. hydrolysis of NMEPT) was allowed to complete a period of more than 50 half-lives at $30{ }^{\circ} \mathrm{C}$. The hydrolysis of hydrolytic product (NMPA) of NMEPT, was then initiated by adding $0.2 \mathrm{ml}$ of $1.25 \mathrm{M} \mathrm{HCl}$ to the reaction mixture. The resulting reaction mixture, having a total volume of $5.0 \mathrm{ml}$, contained $2 \times 10^{-3} \mathrm{M}$ NMPA (assuming $100 \%$ conversion of NMEPT to NMPA within a period of $>50$ half-lives for $k_{1 \mathrm{obs}}$-step) and $0.03 \mathrm{M} \mathrm{HCl}$. The change in $A_{\text {obs }}$ at $310 \mathrm{~nm}$ was monitored as a function of reaction time, $t$, using either a diode-array or Shimadzu UV-visible spectrophotometer.

\section{Kinetic data analysis}

A monotonic increase in $A_{\text {obs }}$ in the initial phase of the reaction (hydrolysis of NMPA) followed by a monotonic decrease in $A_{\text {obs }}$ in the final phase of the reaction (shown for a typical kinetic run in Fig. 1), observed in almost all kinetic runs, is in agreement with the reaction scheme shown by eqn. (2). The change in $A_{\text {obs }}$ due to change in [PAn] during the course of the reaction is given by eqn. (3) (provided $k_{2 \text { obs }} \neq k_{3 \mathrm{obs}}$ )

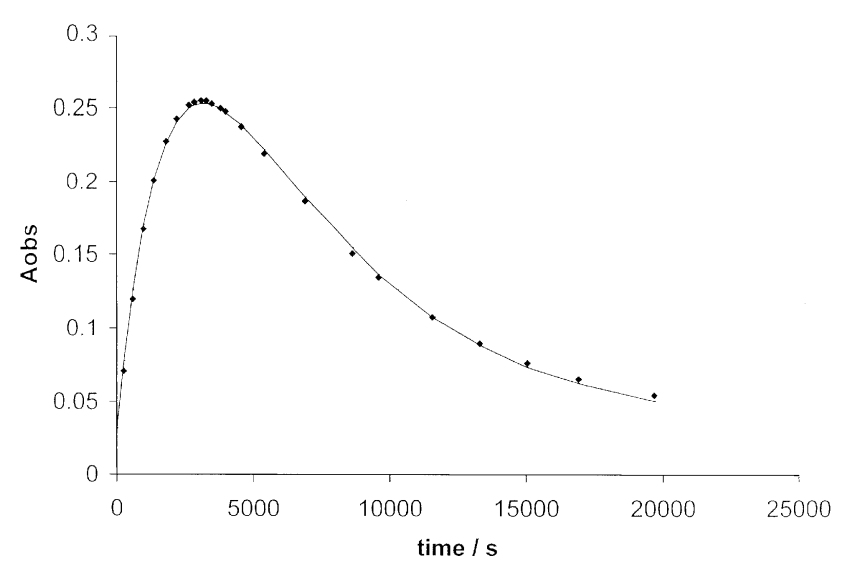

Fig. 1 Plot showing the dependence of observed absorbance ( $A$ obs at $310 \mathrm{~nm})$ versus reaction time $(t)$ for the cleavage NMPA at $30{ }^{\circ} \mathrm{C}$ in mixed aqueous solution containing $2 \times 10^{-3} \mathrm{M}$ NMPA, $60 \% \mathrm{v} / \mathrm{v}$ $\mathrm{CH}_{3} \mathrm{CN}$ and $0.03 \mathrm{M} \mathrm{HCl}$. The solid line is drawn through the least squares calculated data points using eqn. (3) and parameters listed in Table 2 .

$$
A_{\text {obs }}=\frac{\delta_{\text {app }}[\mathrm{X}]_{0} k_{2 \text { obs }}}{k_{3 \text { obs }}-k_{2 \text { obs }}}\left\{\exp \left(-k_{2 \text { obs }} t\right)-\exp \left(-k_{3 \text { obs }} t\right)\right\}+A_{0}
$$

where all the symbols have their usual meanings as described elsewhere. ${ }^{12,13}$ The details of the calculation of $k_{2 \mathrm{obs}}, k_{3 \mathrm{obs}}$ and $\delta_{\text {app }}$ ' from eqn. (3) are also described elsewhere. ${ }^{12,13}$

The values of $k_{2 \text { obs }} / k_{3 \text { obs }}$ change from $>1$ to $<1$ with the change in the $\% \mathrm{v} / \mathrm{v}$ content of $\mathrm{CH}_{3} \mathrm{CN}$ within its range $20-80 \%$ $\mathrm{v} / \mathrm{v}$ in mixed aqueous solvent. Thus, at a certain content of $\mathrm{CH}_{3} \mathrm{CN}, k_{2 \text { obs }} / k_{3 \text { obs }}$ may be very close to 1 and when $k_{2 \text { obs }} / k_{3 \text { obs }}=$ 1, the change in $A_{\text {obs }}$ due to change in [PAn] as a function of reaction time, $t$, is given by

$$
A_{\text {obs }}=k t[\mathrm{X}]_{0} \delta_{\text {app }}{ }^{\prime} \exp (-k t)+A_{0}
$$

where $k=k_{2 \text { obs }}=k_{3 \text { obs }}$. The nonlinear least squares technique may be used to calculate $k, \delta_{\text {app }}{ }^{\prime}$ and $A_{0}$ from eqn. (4).

\section{Results and discussion}

(a) Effects of mixed $\mathrm{H}_{2} \mathrm{O}-\mathrm{CH}_{3} \mathrm{CN}$ solvents on the rate of alkaline hydrolysis of $\mathrm{N}$-methoxyphthalimide (NMEPT). In order to know an approximate number of half-life periods for the complete $(\sim 100 \%)$ conversion of $N$-methoxyphthalimide to NMPA at different contents of $\mathrm{CH}_{3} \mathrm{CN}$ in mixed aqueous solvents, a few kinetic runs for the hydrolysis of NMEPT were carried out at $0.001 \mathrm{M} \mathrm{NaOH}$ and $30{ }^{\circ} \mathrm{C}$ in mixed $\mathrm{H}_{2} \mathrm{O}-\mathrm{CH}_{3} \mathrm{CN}$ solvents with $\mathrm{CH}_{3} \mathrm{CN}$ content range $10-80 \%$ v/v. Pseudofirst-order rate constants $\left(k_{\text {obs }}\right)$ for hydrolysis of NMEPT are summarized in Table 1. The nonlinear decrease in $k_{\text {obs }}$ with the increase in $\mathrm{CH}_{3} \mathrm{CN}$ content is not an unusual observation for such bimolecular reactions involving a neutral reactant and a negatively charged reactant $\left(\mathrm{HO}^{-}\right)$. Although theoretical explanations for solvent effects on rates of organic reactions are difficult to provide, some qualitative explanations could be given for such observations. ${ }^{13,16}$ However, an empirical approach to provide empirical explanations for such data may be considered of some importance because of its predictive power of giving the value of dependent variable (such as rate constant) at any known value of independent variable (such as $\% \mathrm{v} / \mathrm{v}$ content of acetonitrile in the present case). The values of 
Table 1 Effect of $\left[\mathrm{CH}_{3} \mathrm{CN}\right]$ on $k_{1 \mathrm{obs}}, \delta_{\text {app }}$ and $A_{\infty}$ calculated from eqn. (1), for the cleavage of NMEPT in an alkaline medium ${ }^{a}$

\begin{tabular}{|c|c|c|c|c|c|}
\hline$\left[\mathrm{CH}_{3} \mathrm{CN}\right] \%, \mathrm{v} / \mathrm{v}$ & $10^{3} k_{1 \mathrm{obs}} / \mathrm{s}^{-1}$ & $\delta_{\text {app }} / \mathrm{M}^{-1} \mathrm{~cm}^{-1}$ & $A_{\infty}$ & $t^{b} / \mathrm{s}$ & $10^{3} k_{1 \mathrm{cald}}{ }^{c} / \mathrm{s}^{-1}$ \\
\hline 10 & $78.0 \pm 2.8^{d}$ & $1783 \pm 74^{d}$ & $0.059 \pm 0.001^{d}$ & 363 & 78.7 \\
\hline 20 & $62.5 \pm 2.0$ & $1694 \pm 62$ & $0.064 \pm 0.001$ & 993 & 58.7 \\
\hline 30 & $39.6 \pm 1.0$ & $1594 \pm 53$ & $0.059 \pm 0.002$ & 703 & 43.7 \\
\hline 40 & $32.0 \pm 1.0$ & $1581 \pm 44$ & $0.064 \pm 0.001$ & 1028 & 32.6 \\
\hline 50 & $24.0 \pm 0.8$ & $1590 \pm 33$ & $0.065 \pm 0.002$ & 728 & 24.3 \\
\hline 60 & $18.7 \pm 1.0$ & $1506 \pm 39$ & $0.062 \pm 0.003$ & 1248 & 18.1 \\
\hline 70 & $13.3 \pm 1.0$ & $1428 \pm 47$ & $0.064 \pm 0.005$ & 1248 & 13.5 \\
\hline 80 & $12.9 \pm 2.0$ & $1132 \pm 78$ & $0.085 \pm 0.002$ & 1248 & 10.1 \\
\hline
\end{tabular}

${ }^{a}[\mathrm{NMEPT}]_{0}=2 \times 10^{-4} \mathrm{M},[\mathrm{NaOH}]=0.001 \mathrm{M}$, mixed $\mathrm{H}_{2} \mathrm{O}-\mathrm{CH}_{3} \mathrm{CN}$ solvent, $30{ }^{\circ} \mathrm{C}, \lambda=300 \mathrm{~nm} .{ }^{b}$ Maximum reaction time attained in the kinetic run. ${ }^{c}$ Calculated from eqn. (5) with $k_{10}=0.106 \mathrm{~s}^{-1}$ and $\Psi=2.93 \times 10^{-2}(\% \mathrm{v} / \mathrm{v})^{-1} \cdot{ }^{d}$ Error limits are standard deviations.

Table 2 Effect of [ $\left.\mathrm{CH}_{3} \mathrm{CN}\right]$ on $k_{2 \mathrm{obs}}, k_{3 \mathrm{obs}}$ and $\delta_{\text {app }}{ }^{\prime}$, calculated from eqn. (3), for the cleavage of NMPA in an acidic medium ${ }^{a}$

\begin{tabular}{|c|c|c|c|c|c|c|c|c|}
\hline$\left[\mathrm{CH}_{3} \mathrm{CN}\right](\% \mathrm{v} / \mathrm{v})$ & $10^{4} k_{2 \mathrm{obs}} / \mathrm{s}^{-1}$ & $10^{5} k_{3 \mathrm{obs}} / \mathrm{s}^{-1}$ & $\delta_{\text {app }}{ }^{\prime} / \mathrm{M}^{-1} \mathrm{~cm}^{-1}$ & $A_{0}^{b}$ & $A_{\text {fin }}{ }^{c}$ & $A_{\max }^{d}$ & $t^{e} / \mathrm{s}$ & $10^{5} k_{\mathrm{obs}}^{f} / \mathrm{s}^{-1}$ \\
\hline 20 & $\begin{array}{l}1.21 \pm 0.12^{g} \\
2.61^{h}\end{array}$ & $\begin{array}{l}576 \pm 53^{g} \\
637\end{array}$ & $\begin{array}{l}1960 \pm 270^{g} \\
1080(610)^{i}\end{array}$ & $\begin{array}{l}0.060 \\
0.060(0.051)\end{array}$ & 0.098 & 139 & 9935 & 637 \\
\hline 30 & $2.53 \pm 0.31$ & $287 \pm 30$ & $876 \pm 146(514)$ & $0.020(0.014)$ & 0.042 & 0.145 & 15880 & 328 \\
\hline 40 & $2.47 \pm 0.12$ & $160 \pm 9$ & $706 \pm 51(379)$ & $0.022(0.017)$ & 0.033 & 0.181 & 17040 & 162 \\
\hline 50 & $2.01 \pm 0.10$ & $90.8 \pm 5.1$ & $653 \pm 46(308)$ & $0.013(0.004)$ & 0.032 & 0.204 & 17164 & 90.5 \\
\hline 60 & $1.73 \pm 0.05$ & $52.0 \pm 1.9$ & $575 \pm 24(254)$ & $0.032(0.017)$ & 0.055 & 0.255 & 19670 & 38.8 \\
\hline 70 & $2.15 \pm 0.51$ & $16.7 \pm 3.9$ & $296 \pm 66(217)$ & $0.030(0.037)$ & 0.095 & 0.278 & 19735 & 16.3 \\
\hline 80 & $1.37 \pm 0.12$ & $6.69 \pm 0.72$ & $295 \pm 23(171)$ & $0.030(0.026)$ & 0.261 & 0.327 & 19670 & 6.1 \\
\hline
\end{tabular}

${ }^{a}[\mathrm{NMPA}]_{0}=2 \times 10^{-3} \mathrm{M},[\mathrm{HCl}]=0.03 \mathrm{M}$, mixed $\mathrm{H}_{2} \mathrm{O}-\mathrm{CH}_{3} \mathrm{CN}$ solvent, $30{ }^{\circ} \mathrm{C}, \lambda=310 \mathrm{~nm} .{ }^{b}$ Parenthesized values were obtained by extrapolation of $A_{\text {obs }}$ values to reaction time $t=0 .{ }^{c}$ These values represent $A_{\text {obs }}$ at maximum reaction time attained in the kinetic run. ${ }^{d}$ Observed maximum

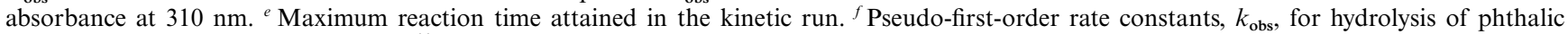
anhydride at $0.005 \mathrm{M} \mathrm{HCl}$, and $30{ }^{\circ} \mathrm{C}^{11}$ (it should be noted that pseudo-first-order rate constants, $k_{\text {obs }}$, were found to be almost unchanged with change in $[\mathrm{HCl}]$ from 0.005 to $1.0 \mathrm{M}$ in aqueous solvents containing $\left.2 \% \mathrm{CH}_{3} \mathrm{CN}^{11}\right) .{ }^{g}$ Error limits are standard deviations. ${ }^{h}$ This value of $k_{2}$ obs was calculated from the relationship: $k_{2 \text { obs }}=k_{3 \mathrm{obs}} / \chi$ with $10^{4} k_{3 \mathrm{obs}}=63.7 \mathrm{~s}^{-1}$ and $\chi=24$. The value of $\chi(=24)$ was calculated from eqn. (6) (as described in the text) with $A_{\text {obs,cor }}{ }_{\text {max }}=0.059,[\mathrm{X}]_{0}=0.002 \mathrm{M}$ and $\delta_{\text {app }}{ }^{\prime}=1080 \mathrm{M}^{-1} \mathrm{~cm}^{-1}$. ${ }^{i}$ Values in parentheses were obtained from the hydrolysis of phthalic anhydride at $0.005 \mathrm{M} \mathrm{HCl}$ and $30^{\circ} \mathrm{C}^{11}$

$k_{\text {1obs }}$ fit reasonably well (as is evident from the least squares calculated values of $k_{1 \text { cald }}$, Table 1) to the following empirical equation

$$
k_{1 \mathrm{bbs}}=k_{10} \exp (-\Psi[\mathrm{OCS}])
$$

where $k_{10}$ and $\Psi$ are empirical constants and [OCS] $=\% \mathrm{v} / \mathrm{v}$ content of organic co-solvent (acetonitrile) in mixed aqueous solvent. The nonlinear least squares calculated values of $k_{10}$ and $\Psi$ are $\left(106 \pm 4 \mathrm{~s}^{-1}\right) \times 10^{-3} \mathrm{~s}^{-1}$ and $(2.93 \pm 0.15) \times 10^{-2}(\% \mathrm{v} / \mathrm{v})^{-1}$.

(b) Acidic aqueous cleavage of NMPA in mixed aqueousacetonitrile solvents. Several kinetic runs were carried out within the $\mathrm{CH}_{3} \mathrm{CN}$ content range $20-80 \%$ v/v at $0.03 \mathrm{M} \mathrm{HCl}$ and $30{ }^{\circ} \mathrm{C}$. The observed kinetic data $\left(A_{\text {obs }}\right.$ versus $\left.t\right)$ were used to calculate $k_{2 \mathrm{obs}}, k_{3 \mathrm{obs}}$, and $\delta_{\text {app }}$ ' from eqn. (3) at a most appropriate value of $A_{0}$. These calculated kinetic parameters at different contents of $\mathrm{CH}_{3} \mathrm{CN}$ are summarized in Table 2. Although the observed data $\left(A_{\text {obs }}\right.$ versus $\left.t\right)$ at $20 \% \mathrm{v} / \mathrm{v} \mathrm{CH}_{3} \mathrm{CN}$ showed a satisfactory fit to eqn. (3) in terms of per cent residual error, RE (= $\left.100\left(A_{\text {obs i }}-A_{\text {calcd i }}\right) / A_{\text {obs i }}\right)$ with maximum $\mathrm{RE}$ value of $\sim 4 \%$ in the vicinity of the maximum in $A_{\mathrm{obs}}$ versus $t$ profile, the value of $\delta_{\text {app }}{ }^{\prime}\left(=1960 \mathrm{M}^{-1} \mathrm{~cm}^{-1}\right)$ is rather high compared to $\delta_{\text {app }}{ }^{\prime}$ $\left(=610 \mathrm{M}^{-1} \mathrm{~cm}^{-1}\right)$ obtained for hydrolysis of PAn under similar experimental conditions. The most obvious cause for this is the significantly low value of $A_{\mathrm{obs}}{ }^{\max }$ obtained at $t_{\max }$ where $t_{\max }$ is defined as the reaction time at which [PAn] becomes maximum during the course of such consecutive reactions. A low value of $A_{\text {obs }}{ }^{\text {max }}(=0.139)$ is due to a significantly large value of $k_{3 \mathrm{obs}} / k_{2 \mathrm{obs}}$ at $20 \% \mathrm{v} / \mathrm{v} \mathrm{CH}_{3} \mathrm{CN}$. Perhaps, an alternative kinetic analysis of these observed data carried out by a procedure described elsewhere for similar observations ${ }^{11}$ may provide a more reliable value of $k_{2 \text { obs }}$.

For an irreversible first-order consecutive reaction as shown by eqn. (2), $A_{\text {obs }}{ }^{\text {max }}$ is related to rate constants $k_{2 \text { obs }}$ and $k_{3 \text { obs }}$ by eqn. (5) ${ }^{11,17}$

$$
A_{\text {obs,cor }}^{\max }=[\mathrm{X}]_{0} \delta_{\text {app }}{ }^{\prime} \chi^{\chi /(1-\chi)}
$$

where $\chi=k_{3 \mathrm{obs}} / k_{2 \mathrm{obs}}$ and $A_{\text {obs,cor }}^{\max }=A_{\mathrm{obs}}^{\max }-A_{0}$. Equation (5) is valid for all values of $\chi$ except $\chi=1$. The rearrangement of eqn. (5) gives eqns. (6) and (7)

$$
\begin{gathered}
\chi=\exp \left[\left(\frac{1-\chi}{\chi}\right) \ln \left(\frac{A_{\text {obs,cor }}^{\max }}{[\mathrm{X}]_{0} \delta_{\text {app }}{ }^{\prime}}\right)\right] \\
\chi=\frac{(1-\chi) \ln \left[A_{\mathrm{obs}, \mathrm{cor}}^{\max } /\left([\mathrm{X}]_{0} \delta_{\text {app }}{ }^{\prime}\right)\right]}{\ln \chi}
\end{gathered}
$$

The value of $\chi$ can be calculated from eqn. (6) if $\chi>1$ and eqn. (7) if $\chi<1$ by the use of the method of iteration ${ }^{18}$ provided $A_{\text {obs,cor }}{ }^{\max },[\mathrm{X}]_{0}$ and $\delta_{\text {app }}{ }^{\prime}$ are known. For a typical kinetic run at $20 \% \mathrm{v} / \mathrm{v} \mathrm{CH} \mathrm{CH}_{3} \mathrm{CN}, A_{\text {obs,cor }}{ }_{\text {max }}=0.059$ (obtained from the observed absorbance at $t_{\max }$ and $A_{0}$ value), $[\mathrm{X}]_{0}=0.002 \mathrm{M}$ and $\delta_{\text {app }}{ }^{\prime}=$ $1080 \mathrm{M}^{-1} \mathrm{~cm}^{-1}$ (obtained from the extrapolation of the plot of $\delta_{\text {app }}{ }^{\prime}$ versus $\% \mathrm{v} / \mathrm{v}$ content of $\mathrm{CH}_{3} \mathrm{CN}$ ). These values of $A_{\text {obs,cor }}{ }^{\text {max }},[\mathrm{X}]_{0}$ and $\delta_{\text {app }}{ }^{\prime}$ were used to calculate $\chi$ from eqn. (6) by using the method of iteration. ${ }^{18}$ The values of $\chi(=24)$ and $k_{3 \text { obs }}\left(=637 \times 10^{-5} \mathrm{~s}^{-1}\right.$, obtained from ref. 18), gave $k_{2 \mathrm{obs}}=$ $26.1 \times 10^{-5} \mathrm{~s}^{-1}$ which is also showed in Table 2 .

The values of $k_{2 \text { obs }}$ are almost independent of $\mathrm{CH}_{3} \mathrm{CN}$ content within the range $20-70 \% \mathrm{v} / \mathrm{v}$. But the value of $k_{2 \text { obs }}$ at $80 \%$ v/v $\mathrm{CH}_{3} \mathrm{CN}$ is nearly $40 \%$ lower than those obtained at $\leq 70 \%$ $\mathrm{v} / \mathrm{v} \mathrm{CH}_{3} \mathrm{CN}$. However, $k_{2 \text { obs }}$ values for the acidic aqueous cleavage of OCBA remained almost independent of $\mathrm{CH}_{3} \mathrm{CN}$ content within the range $20-80 \% \mathrm{v} / \mathrm{v}^{12}$ The values of $k_{3 \mathrm{obs}}$ are comparable with pseudo-first-order rate constants for hydrolysis of PAn obtained under similar experimental conditions ${ }^{19}$ (Table 2 ). The rate constant $k_{3 \text { obs }}$ decreased by nearly 100 -fold while $k_{2 \text { obs }}$ remained almost unchanged with the increase in $\mathrm{CH}_{3} \mathrm{CN}$ content from 20 to $80 \% \mathrm{v} / \mathrm{v}$. These observations show that the 
rates of intramolecular and intermolecular nucleophilic reactions involving neutral reactants or reaction sites are almost insensitive and highly sensitive, respectively, to the change in the relative permittivity of the reaction medium.

Although the values of $\delta_{\text {app }}{ }^{\prime}$ at different $\mathrm{CH}_{3} \mathrm{CN}$ contents are dissimilar to the corresponding $\delta_{\text {app }}$ 'values obtained from acidic hydrolysis of PAn, they are, however, not very different from each other and the trend of variation of $\delta_{\text {app }}{ }^{\prime}$ with the change in $\mathrm{CH}_{3} \mathrm{CN}$ content is the same (Table 2). One possible explanation of this marked dissimilarity is the high sensitivity of $\delta_{\text {app }}$ 'values to $A_{0}$ values. For example, at $40 \% \mathrm{v} / \mathrm{v} \mathrm{CH}_{3} \mathrm{CN}$ for NMPA, a change in $A_{0}$ from 0.020 to 0.025 changed $k_{2 \text { obs }}, k_{3 \text { obs }}$, $\delta_{\text {app }}{ }^{\prime}$ and $\Sigma d_{\mathrm{i}}^{2}$ (where $d_{\mathrm{i}}=A_{\text {obs i }}-A_{\text {calcd i }}$ ) from $23.7 \times 10^{-5} \mathrm{~s}^{-1}$, $164 \times 10^{-5} \mathrm{~s}^{-1}, 756 \mathrm{M}^{-1} \mathrm{~cm}^{-1}$ and $3.57 \times 10^{-4}$ to $26.3 \times 10^{-5} \mathrm{~s}^{-1}$, $152 \times 10^{-5} \mathrm{~s}^{-1}, 636 \mathrm{M}^{-1} \mathrm{~cm}^{-1}$ and $3.65 \times 10^{-4}$, respectively. However, these and similar calculated values show that the values of $k_{2 \mathrm{obs}}$ and $k_{3 \mathrm{obs}}$ are less sensitive to $A_{0}$ values.

The general mechanism for the acidic cleavage of phthalamic, $N$-substituted phthalamic acids ${ }^{16,7,8}$ and related compounds ${ }^{6,9}$ is shown in Scheme 2. The other probable routes for the formation of $\mathbf{4}^{ \pm}$have been ruled out based upon qualitative conclusions and the $k_{4}{ }^{2}$-step has been concluded to be the rate-determining step. ${ }^{11}$<smiles>[R]NC(=O)c1ccccc1C(=O)O</smiles><smiles>[R]N[C@]1([O-])OC(=O)c2ccccc21</smiles>

$\mathrm{PAn}+\mathrm{RNH}_{2}$

$$
k_{-2}^{2} \| k_{2}^{2}
$$<smiles>[R]NC1(O)OC(=O)c2ccccc21</smiles>

4

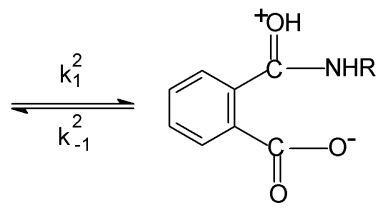

Scheme 2

An approximately 10 -fold larger value of $k_{2 \text { obs }}$ for hydrolysis of OCBA compared with phthalamic acid has been described as co-operative (also called 'synergistic') catalysis where the oxygen of the $-\mathrm{NHOH}$ moiety was proposed to act as a conduit for the transfer of a proton from the $o-\mathrm{COOH}$ group to the carbonyl oxygen of $\mathrm{CONHOH}$ group in a fast equilibrium process. This process activated the carbonyl carbon for intramolecular nucleophilic attack by anionic oxygen of $o-\mathrm{COO}^{-}$ group to form a reactive tetrahedral intermediate similar to 4 . In view of this proposed mechanism, the value of $k_{2 \mathrm{obs}}$ for hydrolysis of OCBA is expected to be larger by only $\sim 2$-fold (due to a statistical factor of 2) compared to that for hydrolysis of NMPA because $\sigma^{*}{ }_{\mathrm{OH}}$ is similar to $\sigma^{*}{ }_{\mathrm{OMe}}{ }^{20}$ The similarity of $\sigma^{*}{ }_{\mathrm{OH}}$ and $\sigma_{\mathrm{OMe}}^{*}$ is also evident from the $\mathrm{p} K_{\mathrm{a}}$ values of a number of $\mathrm{HORNR}{ }_{1} \mathrm{R}_{2} \mathrm{H}^{+}$and MeORNR $\mathrm{R}_{2} \mathrm{H}^{+}$acids. ${ }^{21}$

Thus, nearly 10 -fold larger value of $k_{2 \text { obs }}$ for hydrolysis of OCBA than that for NMPA indicate the occurrence of a different mechanism in the acidic aqueous cleavage of OCBA and NMPA. The most appropriate mechanisms for the cleavage of NMPA and OCBA in acidic aqueous medium are shown in Schemes 2 (where $\mathrm{R}=\mathrm{OCH}_{3}$ ) and 3, respectively. However, the conversion of $\mathbf{T}_{\mathbf{1}}$ to products through the transition state $\mathbf{T S}_{\mathbf{1}}$<smiles></smiles><smiles>C#CC</smiles>

OCBA

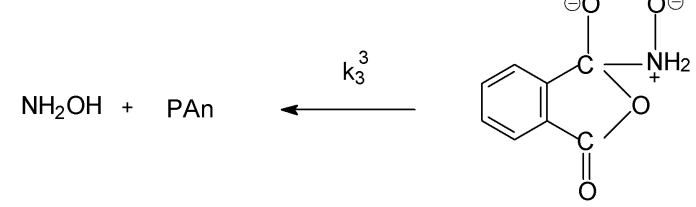

Scheme 3

cannot be completely ruled out. The present data are also not sufficient to rule out the formation of $\mathbf{4}$ from $T_{1}$ (where $R=O H$ ) through a solvent assisted proton switch mechanism. The value of $k_{2 \text { obs }}$ for hydrolysis of NMPA should be smaller than that for hydrolysis of phthalamic acid because of expected negative value of $\rho^{*}$ and $\sigma^{*}{ }_{\mathrm{H}}(=0.49)^{20}$ is significantly smaller than $\sigma_{\text {OMe }}^{*}(=1.80){ }^{20}$ But the observed value of $k_{2 \text { obs }}$ for hydrolysis of NMPA (Table 2) is similar to that for phthalamic acid. ${ }^{13}$ These results show the possible stabilization of intermediate 4 due to probable internal hydrogen bonding as shown in $\mathbf{3}$.

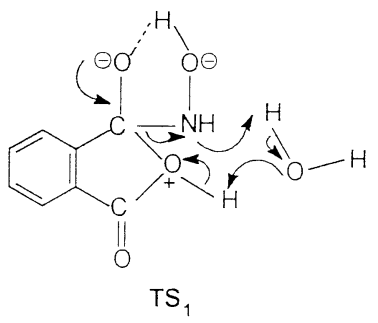

\section{Acknowledgements}

We wish to thank the Universiti Malaya for financial support (Vote F0375/2001B and Vote F0718/2002B).

\section{References}

1 (a) M. L. Bender, J. Am. Chem. Soc., 1957, 79, 1258; (b) M. L. Bender, Y.-L. Chow and F. Chloupek, J. Am. Chem. Soc., 1958, 80, 5380 .

2 M. Morawetz and J. A. Shafer, J. Am. Chem. Soc., 1962, 84, 3783.

3 J. Brown, S. C. K. Su and J. A. Shafer, J. Am. Chem. Soc., 1966, 88, 4468 .

4 (a) T. Higuchi, T. Miki, A. C. Shah and A. K. Herd, J. Am. Chem. Soc., 1963, 85, 3655; (b) T. Higuchi, L. Eberson and A. K. Herd, J. Am. Chem. Soc., 1966, 88, 3805.

5 G. Dahlgren and N. L. Simmerman, J. Phys. Chem., 1965, 89, 3626.

6 (a) M. F. Aldersley, A. J. Kirby and P. W. Lancaster, J. Chem. Soc., Chem. Commun., 1972, 570; (b) A. J. Kirby and P. W. Lancaster, J. Chem. Soc. Perkin Trans. 2, 1972, 1206; (c) A. J. Kirby, R. S. McDonald and C. R. Smith, J. Chem. Soc., Perkin Trans. 2, 1974, 1495; (d) M. F. Aldersley, A. J. Kirby, P. W. Lancaster, R. S. McDonald and C. R. Smith, J. Chem. Soc., Perkin Trans. 2, 1974, 1487.

7 M. W. Hawkins, J. Chem. Soc., Perkin Trans. 2, 1976, 642.

8 R. A. M. Blackburn, B. Capon and A. C. McRitchie, Bioorg. Chem., 1977, 6, 71

9 R. Kluger and C.-H. Lam, J. Am. Chem. Soc., 1975, 97, 5536; R. Kluger and C.-H. Lam, J. Am. Chem. Soc., 1978, 100, 2191.

10 F. M. Menger and M. Ladika, J. Am. Chem. Soc., 1988, 110, 6794. 
11 M. N. Khan, Indian J. Chem. Sect. A: Inorg. Bio-inorg. Phys. Theor. Anal. Chem., 1993, 32, 395.

12 M. N. Khan, J. Phys. Org. Chem., 1998, 11, 216

13 M. N. Khan, J. Org. Chem., 1996, 61, 8063.

14 M. N. Khan, Int. J. Chem. Kinet., 1991, 23, 567.

15 M. N. Khan, J. Chem. Soc., Perkin Trans. 2, 1990, 435.

$16 \mathrm{~J}$. B. F. N. Engberts, in Water A Comprehensive Treatise, ed. F. Franks, Plenum, New York, 1979, Vol. 6. p. 139.

17 A. A. Frost and R. G. Pearson, Kinetics and Mechanism, Wiley, New York, 1961, p. 168.
18 J. B. Scarborough, Numerical Mathematical Analysis, Oxford \& IBH Calcutta, 1966, p. 208.

19 M. N. Khan, Indian J. Chem. Sect. A: Inorg. Bio-inorg. Phys., Theor. Anal. Chem., 1993, 32, 387.

20 J. Hine, Structural Effects on Equilibria in Organic Chemistry; Wiley, New York, 1975, p. 91

21 (a) J. Hine and M. N. Khan, J. Am. Chem. Soc., 1977, 99, 3847 and references cited therein; (b) M. N. Khan, J. Chem. Soc., Perkin Trans. $2,1990,675$. 